\title{
Feeding the Pipeline: Academic Skills Training for Predental Students
}

\author{
Geraldine Markel, Ph.D.; Marilyn Woolfolk, D.D.S., M.P.H.; \\ Marita Rohr Inglehart, Dr.phil.habil.
}

\begin{abstract}
This article reports the outcomes of an evaluation conducted to determine if an academic skills training program for undergraduate predental students from underrepresented minority backgrounds increased the students' standardized academic skills test scores for vocabulary, reading comprehension, reading rates, spelling, and math as well as subject-specific test results in biology, chemistry, and physics. Data from standardized academic skill tests and subject-specific tests were collected at the beginning and end of the 1998 to 2006 Pipeline Programs, six-week summer enrichment programs for undergraduate predental students from disadvantaged backgrounds. In total, 179 students (75.4 percent African American, 7.3 percent Hispanic, 5.6 percent Asian American, 5 percent white) attended the programs during these nine summers. Scores on the Nelson-Denny Reading Test showed that the students improved their vocabulary scores (percentile ranks before/after: 46.80 percent $/ 59.56$ percent; $p<.001$ ), reading comprehension scores (47.21 percent/62.67 percent; $p<.001)$, and reading rates $(34.01$ percent/78.31 percent; $p<.001)$ from the beginning to the end of the summer programs. Results on the Wide Range Achievement Test III showed increases in spelling (73.58 percent/86.22 percent; $\mathrm{p}<.001)$ and math scores (56.98 percent $/ 81.28$ percent; $\mathrm{p}<.001)$. The students also improved their subject-specific scores in biology (39.07 percent/63.42 percent; $p<.001)$, chemistry $(20.54$ percent/51.01 percent; $p<.001)$, and physics (35.12 percent/61.14 percent; $\mathrm{p}<.001)$. To increase the number of underrepresented minority students in the dental school admissions pool, efforts are needed to prepare students from disadvantaged backgrounds for this process. These data demonstrate that a six-week enrichment program significantly improved the academic skills and basic science knowledge scores of undergraduate predental students. These improvements have the potential to enhance the performance of these students in college courses and thus increase their level of competitiveness in the dental school admissions process.
\end{abstract}

Dr. Markel is Educational Consultant, School of Dentistry, University of Michigan; Dr. Woolfolk is Assistant Dean for Student Services and Professor of Dentistry, Department of Periodontics and Oral Medicine, School of Dentistry, University of Michigan; and Dr. Inglehart is Associate Professor of Dentistry, Department of Periodontics and Oral Medicine, School of Dentistry and Adjunct Associate Professor of Psychology, Department of Psychology, College of Literature, Science, and Arts, University of Michigan. Direct correspondence and requests for reprints to Dr. Marita Rohr Inglehart, Department of Periodontics and Oral Medicine, School of Dentistry, University of Michigan, 1011 North University Avenue, Ann Arbor, MI 48109-1078; 734-763-8073 phone; 734-763-5503 fax; mri@umich.edu.

Key words: predental students, underrepresented minority students, dental students, medical students, admissions, academic skills, study skills, enrichment programs, medical education, dental education

Submitted for publication 12/3/07; accepted 3/5/08

$\mathrm{I}$ n September 2004, the Sullivan Commission published a report entitled Missing Persons: Minorities in the Health Professions. ${ }^{1}$ This report provided a comprehensive overview of the situation of underrepresented minority students (URMS) and providers in the health care professions. Above all, it highlighted the fact that there is a diversity gap between the percentages of U.S. citizens and the percentages of health care providers from URM backgrounds. While African Americans, Hispanics, and American Indians represent more than 25 percent of the U.S. population, only 9 percent of nurses, 6 percent of physicians, and 5 percent of dentists are from these backgrounds. In addition, less than 10 percent of nursing faculties, 8.6 percent of dental fac- ulties, and only 4.2 percent of medical faculties come from these URM groups. Given this disparity among both health care providers and health care faculty members, it seems crucial to increase the number of students from URM backgrounds in health professional schools. However, the enrollment numbers of URM students in medical and dental schools show that this is not occurring. Indeed, the annual number of medical students from URM backgrounds actually decreased from 1,857 (11.6 percent) in 1998 to 1,724 (11.0 percent) in 2002. ${ }^{2}$ In dental education, the trends are comparable. The percentage of URMS in dental schools was actually higher in the early 1990s (1990-91:14.08 percent; 1991-92: 13.5 percent; 1992-93: 13.4 percent) than in more recent years 
(2001-02: 11.19 percent; 2002-03:11.59 percent; 2003-04: 11.72 percent). ${ }^{1}$

A major concern therefore is the question of how the number of URMS can be increased in medical and dental schools. There seems to be a consensus that recruitment efforts have to start early and must be accompanied by programs that ensure the URM applicants are ready to compete in the applicant pools for these very competitive programs. Summer enrichment programs for undergraduate students have been reported in the literature at several medical schools including the New Jersey Medical School, ${ }^{3}$ Medical College of Georgia, ${ }^{4}$ and University of North Carolina at Chapel Hill ${ }^{5}$ and at such dental schools as the Oregon Health \& Science University School of Dentistry ${ }^{6}$ and the University of Michigan School of Dentistry. ${ }^{7-18}$ Some professional schools conduct a program for premedical and predental students combined; such a program started in 1969 at Meharry Medical College. ${ }^{19}$ In 2004, Gravely et al. analyzed enrichment and recruitment programs at dental schools and identified twenty-three in the United States. ${ }^{20}$ More recently, the Robert Wood Johnson Foundation sponsored a Dental Pipeline Program ${ }^{21}$ that resulted in a number of summer enrichment programs for undergraduate students.

While all these efforts have the same objective of increasing the numbers of URMS in the health professional schools,${ }^{20}$ they differ in the specific programs they offer. At the University of Michigan School of Dentistry, summer enrichment programs started in 1994 with the support of a Health Careers Opportunity Program (HCOP) grant. The first effort, called the Profile for Success (PFS) Program, was developed for junior and senior undergraduate students and had the goal of preparing them for taking the Dental Admission Test (DAT). However, it became obvious that an additional enrichment program for first- and second-year undergraduate students was needed to improve the students' study skills and their background in the basic sciences (biology, chemistry, and physics). An analysis of the PFS participants' academic records suggested that these students needed mentoring to ensure they would engage in an appropriate course of studies that would support their dental school applications. Supported by a subsequent HCOP grant, a new program called the Pipeline Program offered by the University of Michigan School of Dentistry was therefore added in 1998 as a complement to the PFS program. The Pipeline Program was a six-week summer enrichment program for first- and second-year undergraduate students who wanted to enter dental or medical school programs. It focused on improving students' reading and study skills, preparing them for natural science classes with content-specific courses in biology, chemistry, and physics, and introducing them to the dental school environment and the dental school admissions process.

The objective of this article is to describe the academic enrichment component of the Pipeline Program at the University of Michigan School of Dentistry and to analyze the progress students made from the beginning to the end of the six-week program. The program was conducted from 1998 to 2006, at which time HCOP funding was terminated. The data collected from the program participants in those nine years were used to evaluate its effectiveness.

\section{Methods and Materials}

This study was approved by the Institutional Review Board for the Health Sciences at the University of Michigan, Ann Arbor, MI.

Data were collected between 1998 and 2006 for 179 undergraduate students who were interested in a career in dentistry or medicine and participated in the University of Michigan School of Dentistry's Pipeline Program, a six-week summer enrichment program. While most of these students were first- or second-year undergraduate students (54.2 percent and 36.3 percent, respectively), a few students were juniors or seniors (3.9 percent/1.1 percent) or did not report their academic level ( 4.5 percent). Fifty-four of these program participants (30.2 percent) were male, and 124 (69.3 percent) were female. While most students were African American (75.4 percent), some participants were from Hispanic/Latino (7.3 percent), Asian American (5.6 percent), European American (5 percent), or other backgrounds (2.3 percent), whereas 4.5 percent of the participants did not report their race/ethnicity. The size of the program ranged from a minimum of fifteen students in 1998 to a maximum of twenty-five students each in 2004 and 2005.

The Nelson-Denny Reading Test ${ }^{22}$ and the Wide Range Achievement Test, revision $3^{23}$ were administered on the first day of the summer program in a group session with group instructions. Different forms of these same two tests were given again during the first part of the sixth and final week of the program. Immediately after the academic skills baseline assessment, feedback was given to the class 
as a whole. In addition, each individual student met with the academic skills instructor for approximately thirty minutes to gain individual feedback and discuss goals and strategies as well as potential challenges for this particular student. After the students had received their individual results and developed their study plans, all students had ten two-hour class sessions to further develop their academic skills. These sessions covered describing, modeling, and practicing learning and self-management strategies in such areas as advanced reading skills, vocabulary building, time management, test taking, and stress management. During the most recent program in 2006, a specific instruction on math computation skills was added. After each two-hour session, the students received homework materials and had opportunities to study and practice to improve their skills.

In addition to assessing the students' academic skills with standardized tests, subject-specific tests in biology, chemistry, and physics were given at the beginning and end of the programs. Classes with subject-specific instructions were offered on most school days. Opportunities to utilize the academic skills practiced in these content-specific classes were provided as well.

The Nelson-Denny Reading Test (NDRT) ${ }^{22}$ is comprised of two subtests concerning vocabulary and reading abilities (reading comprehension and reading rate). The vocabulary section consists of eighty items, each with five answer choices. The students have fifteen minutes to complete this section of the test. The reading section contains seven reading passages and a total of thirty-eight questions, each with five answer choices. The time limit for this section is twenty minutes, the first minute being used to determine reading rate and the subsequent nineteen to determine reading comprehension. Form $\mathrm{G}$ is administered as the pre-test, and Form $\mathrm{H}$ is administered as the post-test.

The Wide Range Achievement Test, revision 3 (WRAT 3$)^{23}$ measures basic academic skills including spelling words and basic mathematical calculations. It was standardized on a representative national sample ranging in age from five to ninety-four years. The spelling subtest measures an individual's ability to encode sounds into written form through the use of a dictated spelling format containing both letters and words (fifty-five items). In a group format, the instructor pronounces the word and uses it in a sentence. Students record their spelling of the word in the test booklet. For example, at the post-high school level, spelling words include items such as “imperturbable," “acquiesce," and "iridescence.” The math computation section measures an individual's ability to perform basic mathematic computations through calculating written mathematics problems. For example, a post-high school level item requires the student to "Find interest on $\$ 1200$ at $6 \%$ per year for 2 years compounded annually." Students are allowed fifteen minutes to complete fifty-five problems.

The three instructors of the biology, chemistry, and physics classes designed subject-specific tests to assess the students' pre- and post-program achievements. The same tests were administered at the beginning and end of the program.

The repeated measurement multivariate analyses of variance (MANOVA) program of SPSS (version 14.0 ) was used to analyze the data. ${ }^{24}$

\section{Key Features of the Academic Skills Training}

Sound study skills are essential for academic success: they enhance concentration and increase motivation, both of which promote learning and lead to better grades. Students with effective study skills are less likely to be frustrated and more likely to be optimistic and to have a positive sense of control over their learning: ${ }^{25}$ they are therefore likely to be more motivated to study diligently and in a more efficient and effective manner.

The program goals concerning the participants' academic skills were the following: a) to provide information to all participants about their individual level of basic skills as measured with the standardized tests and subject-specific assessments; b) to increase the students' awareness of the impact of these skills on their grades, achievement motivation, and academic success; c) to offer strategies to the participants that would help them improve their academic skills; and d) to evaluate the efficacy of the six-week summer program for URMS.

The academic skills program consisted of two pre- and post-assessment sessions, ten two-hour seminars, and one thirty-minute, one-on-one, feedback/ coaching session with the academic skills instructor. This instructor was an educational psychologist with expertise in reading and learning strategies and certification in reading and special education, who has authored and coauthored books about teaching strategies, learning, and attention disabilities. ${ }^{26,27}$ 
Each seminar included direct instruction, modeling, and practice of behavioral/cognitive strategies to improve basic skills, time management, organization, concentration, memory, and test-taking, all designed according to research on reading and learning. ${ }^{28-33}$ Students received handouts of PowerPoint presentations. In addition, the academic skills training focused on applying strategies to the contentspecific courses in biology, chemistry, and physics in which the students participated concurrently. These mini-courses were taught by doctoral students in their fields. The students were also instructed to apply these strategies to the reading section of the Dental

Table 1. Average Nelson-Denny Reading Test percentile rank scores at the beginning and end of the program

Vocabulary: Percentile Ranks

\begin{tabular}{cccc}
\hline Year & Beginning & End & $p$ \\
\hline 1999 & $48.81 \%$ & $56.38 \%$ & .073 \\
2000 & $35.94 \%$ & $45.88 \%$ & .028 \\
2001 & $62.00 \%$ & $74.31 \%$ & .001 \\
2002 & $50.43 \%$ & $61.05 \%$ & .013 \\
2003 & $54.63 \%$ & $62.75 \%$ & .007 \\
2004 & $45.56 \%$ & $68.84 \%$ & $<.001$ \\
2005 & $43.00 \%$ & $64.16 \%$ & $<.001$ \\
2006 & $38.00 \%$ & $50.32 \%$ & .001 \\
Total & $46.80 \%$ & $59.56 \%$ & .010
\end{tabular}

Reading Comprehension: Percentile Ranks

\begin{tabular}{cccc}
\hline Year & Beginning & End & $p$ \\
\hline 1999 & $48.50 \%$ & $65.19 \%$ & .002 \\
2000 & $38.88 \%$ & $60.00 \%$ & .013 \\
2001 & $68.62 \%$ & $71.39 \%$ & .468 \\
2002 & $52.87 \%$ & $62.65 \%$ & .048 \\
2003 & $46.94 \%$ & $61.88 \%$ & .177 \\
2004 & $46.40 \%$ & $68.68 \%$ & $<.001$ \\
2005 & $39.20 \%$ & $67.32 \%$ & $<.001$ \\
2006 & $39.32 \%$ & $54.64 \%$ & .004 \\
Total & $47.21 \%$ & $62.67 \%$ & .046 \\
& Reading Rate: Percentile Ranks &
\end{tabular}

\begin{tabular}{cccc}
\hline Year & Beginning & End & $p$ \\
\hline 1999 & $38.06 \%$ & $85.25 \%$ & $<.001$ \\
2000 & $26.19 \%$ & $84.00 \%$ & $<.001$ \\
2001 & $48.23 \%$ & $90.46 \%$ & $<.001$ \\
2002 & $34.96 \%$ & $70.28 \%$ & $<.001$ \\
2003 & $37.13 \%$ & $69.88 \%$ & $<.001$ \\
2004 & $34.32 \%$ & $81.76 \%$ & $<.001$ \\
2005 & $42.80 \%$ & $83.68 \%$ & $<.001$ \\
2006 & $20.14 \%$ & $86.55 \%$ & $<.001$ \\
Total & $34.01 \%$ & $78.31 \%$ & $<.001$ \\
\hline
\end{tabular}

Admission Test (DAT) and the Medical College Admission Test (MCAT).

\section{Results}

Three sets of diagnostic scores were obtained at the beginning of the program and then reassessed at the end. The first set of scores included the vocabulary, reading comprehension, and reading rate scores from the NDRT. ${ }^{22}$ Overall, the average percentile rank in the vocabulary subset increased from 46.8 percent at the beginning of the academic skills programs to 59.56 percent at the end $(\mathrm{p}=.01)$ (see Table 1$)$. An analysis of the improvements in eight different years showed that while there was only a tendency for an improvement in the first year of the program (1999: 48.81 percent vs. 56.38 percent; $p=.073$ ), the average scores in all other years significantly improved from the beginning to the end of the program. To gain a better sense of the actual improvement of these students in these years, it might be helpful to consider the change as not just a percentile rank, but also as a grade-equivalent score. An analysis of these grade-equivalent scores showed that the students on average increased from a 14.11 grade-equivalent score (e.g., beginning of sophomore year in college) at the beginning of the program to a 15.48 grade-equivalent score (e.g., middle of junior year in college) at the end of the program. This change indicates that, during the six-week program, the students improved their vocabulary scores by a gradeequivalent of more than one academic year.

The second subtest of the NDRT assesses students' reading comprehension. Overall, the students increased significantly from a percentile rank of 47.21 percent to 62.67 percent ( $p=.046$ ) (see Table 1). This overall improvement in reading comprehension translates into an increase in grade-equivalent scores from 13.96 to 15.66 . These scores indicate that at the beginning of the program the students on average had a reading comprehension equivalent to students at the end of the first year of college, while the end score indicates that after the program they had an average reading comprehension score of students in the middle of their junior year in college. An analysis of the beginning and end scores in the eight separate years showed that the students' scores in 2001 and 2003 did not improve significantly. However, for each of the other six years, a significant improvement in reading comprehension scores was found.

The final subtest of the NDRT is an assessment of students' reading rate. Overall, a significant 
improvement was found from the start to the end of the six-year program (34.01 percent vs. 78.31 percent; $\mathrm{p}<.001)$. These percentile ranks indicate that the students' average number of words read per minute was 210.78 words at the beginning of the program compared to 374.80 words at the end of the program. While the NDRT manual does not provide grade-equivalents for the reading rate scores, it is worthwhile to mention that a 50th percentile for second-year college students would be an average score of 259 words per minute. The average end score of 374.80 words per minute clearly exceeds this average score of second-year college students. A significant improvement in reading rate scores was found for each of the eight years this program has been conducted.

The Wide Range Achievement Test (WRAT) has two subtests: a spelling section and an arithmetic section. ${ }^{23}$ Table 2 shows that, overall, the students' spelling scores improved from a percentile rank of 73.58 percent at the beginning of the program to 86.22 percent at the end $(\mathrm{p}<.001)$. An analysis of each of the eight years found that the students increased their performance significantly from the beginning to the end of the program in five of the eight years, that in the year 2000 they showed a tendency towards a significant improvement, and that they did not significantly improve in 2002 and 2003.

Table 2 also provides the students' percentile ranks of achievement in the arithmetic subtest of the WRAT 3. While the students had an average percentile rank of 56.98 percent at the beginning of the program, the end score was 81.28 percent $(p<.001)$. Each of the eight cohorts of students improved their achievement in this subtest significantly.

Finally, three subject-specific tests were given at the beginning and end of the program. Table 3 shows that the students' achievements in these tests concerning their knowledge in biology, chemistry, and physics improved significantly overall and for each of the eight cohorts. The percentile ranks in biology improved overall from 39.07 percent to 63.42 percent $(p<.001)$. In chemistry, the scores improved from 20.54 percent to 51.01 percent $(\mathrm{p}<.001)$, and in physics from 35.12 percent to 61.14 percent $(\mathrm{p}<.001)$.

\section{Discussion}

If the number of URMS is to be increased in the dental school applicant pool, major efforts are needed early in students' college careers to increase the likelihood that they have the skills needed to obtain competitive grades required for application to professional schools. The students participating in these eight years of the Pipeline Program at the University of Michigan all shared a high level of motivation to make dentistry or medicine their professional future. However, due to the fact that they primarily came from educationally, socially, or financially disadvantaged backgrounds, many of the students lacked systematic study skills and a basic understanding of how to cope with the rigors of higher-level coursework in college or professional schools. Furthermore, some students might know they have gaps in skills despite achieving good grades in most classes. Once the students received support to identify and understand the gaps in their skills, they made impressive and substantial gains in academic skills in a relatively short time period. The rationale underlying the one-on-one counseling sessions with the academic skills instructor was to provide the students with objective information about these gaps in a safe and confidential setting that would allow them to

Table 2. Average percentile rank scores for the Wide Range Achievement Test at the beginning and end of the program

Spelling: Percentile Ranks

\begin{tabular}{cccc}
\hline Year & Beginning & End & $p$ \\
\hline 1999 & $71.69 \%$ & $78.69 \%$ & .007 \\
2000 & $68.69 \%$ & $76.69 \%$ & .073 \\
2001 & $68.92 \%$ & $85.62 \%$ & $<.001$ \\
2002 & $91.39 \%$ & $93.00 \%$ & .324 \\
2003 & $73.59 \%$ & $78.18 \%$ & .220 \\
2004 & $75.32 \%$ & $92.48 \%$ & $<.001$ \\
2005 & $72.68 \%$ & $94.96 \%$ & $<.001$ \\
2006 & $66.36 \%$ & $90.14 \%$ & $<.001$ \\
Total & $73.58 \%$ & $86.22 \%$ & $<.001$
\end{tabular}

Arithmetic: Percentile Ranks

\begin{tabular}{cccc}
\hline Year & Beginning & End & $p$ \\
\hline 1999 & $68.13 \%$ & $84.31 \%$ & $<.001$ \\
2000 & $57.06 \%$ & $82.31 \%$ & .001 \\
2001 & $58.69 \%$ & $78.69 \%$ & .025 \\
2002 & $45.65 \%$ & $84.87 \%$ & $<.001$ \\
2003 & $70.00 \%$ & $78.71 \%$ & $<.001$ \\
2004 & $55.24 \%$ & $90.48 \%$ & $<.001$ \\
2005 & $49.00 \%$ & $76.76 \%$ & $<.001$ \\
2006 & $52.09 \%$ & $74.09 \%$ & $<.001$ \\
Total & $56.98 \%$ & $81.28 \%$ & $<.001$ \\
& & & \\
\hline
\end{tabular}


Table 3. Average subject-specific percentages of correct answers at the beginning and end of the program

Biology: Percentile Ranks

\begin{tabular}{cccc}
\hline Year & Beginning & End & $p$ \\
\hline 1998 & $36.53 \%$ & $70.13 \%$ & $<.001$ \\
1999 & $29.94 \%$ & $46.63 \%$ & $<.001$ \\
2000 & $38.56 \%$ & $50.88 \%$ & $<.001$ \\
2002 & $57.46 \%$ & $82.18 \%$ & $<.001$ \\
2003 & $13.70 \%$ & $29.85 \%$ & $<.001$ \\
2004 & $29.32 \%$ & $60.01 \%$ & $<.001$ \\
2005 & $50.32 \%$ & $80.44 \%$ & $<.001$ \\
2006 & $56.73 \%$ & $87.27 \%$ & $<.001$ \\
Total & $39.07 \%$ & $63.42 \%$ & $<.001$ \\
\multicolumn{4}{c}{ Chemistry: Percentile Ranks } \\
\hline
\end{tabular}

\begin{tabular}{cccc}
\hline Year & Beginning & End & $p$ \\
\hline 1998 & $23.00 \%$ & $74.87 \%$ & $<.001$ \\
1999 & $28.47 \%$ & $79.67 \%$ & $<.001$ \\
2000 & $28.40 \%$ & $69.88 \%$ & $<.001$ \\
2002 & $10.38 \%$ & $21.94 \%$ & $<.001$ \\
2003 & $7.59 \%$ & $14.41 \%$ & $<.001$ \\
2004 & $25.68 \%$ & $61.04 \%$ & $<.001$ \\
2005 & $26.40 \%$ & $51.04 \%$ & $<.001$ \\
2006 & $14.36 \%$ & $35.27 \%$ & $<.001$ \\
Total & $20.54 \%$ & $51.01 \%$ & $<.001$ \\
\multicolumn{4}{c}{ Physics: Percentile Ranks } \\
\hline
\end{tabular}

\begin{tabular}{lrrr}
\hline Year & Beginning & End & $p$ \\
\hline 1998 & $54.87 \%$ & $85.62 \%$ & $<.001$ \\
1999 & $47.56 \%$ & $71.38 \%$ & $<.001$ \\
2000 & $23.94 \%$ & $36.69 \%$ & .001 \\
2002 & $30.63 \%$ & $53.85 \%$ & $<.001$ \\
2003 & $1.37 \%$ & $24.48 \%$ & $<.001$ \\
2004 & $34.76 \%$ & $59.90 \%$ & $<.001$ \\
2005 & $35.88 \%$ & $86.88 \%$ & $<.001$ \\
2006 & $51.91 \%$ & $70.32 \%$ & $<.001$ \\
Total & $35.12 \%$ & $61.14 \%$ & $<.001$
\end{tabular}

Note: No evaluation data were gathered in 2001. However, this educational component was included in the program activities in 2001.

accept this information and set realistic and attainable individual goals for improvement. In addition, the individual meetings offered an opportunity to look at individual transcripts and life situations in order to identify special challenges students might have. Some students were referred for diagnostic evaluations for learning or attention problems, for example, while other students were referred for psychological or physical health screenings.
While the average improvements on all subtests and subject-specific tests were impressive, the reading comprehension and spelling scores did not improve in two years of the program. One explanation for the lack of improvement of the spelling scores in 2002 was a ceiling effect. The students' average spelling score at the beginning of the program was already 91.39 percent-which did not allow for a substantial improvement. This same rationale can be applied for the lack of significant improvement in the reading comprehension score in 2001, which was already rather high at the beginning of the program (68.62 percent). However, the lack of improvement in the spelling scores in 2003 could have been due to a lower level of interest in this particular subject area, compared to interest in other areas in which the students improved significantly. It is obvious that students from less disadvantaged backgrounds with higher skill levels at the beginning of the programs would not have improved as much as these students. However, if students have relatively lower skill levels, it is absolutely crucial for their future success to ensure that they improve their skills.

One issue that should be stressed when discussing how to best prepare students from disadvantaged backgrounds for the dental school admission process is the relevance of reading rate and reading comprehension for academic success and a good performance on the DAT. Sometimes students read so slowly at the beginning of the program that they were not able to finish the test. In addition, it often seemed as if the students had not acquired advanced reading comprehension strategies. It is therefore crucial to assess the students' reading abilities and then to demonstrate to them in concrete ways how to improve their reading skills. In this program, for example, the students practiced their reading skills on the natural science textbooks they used in biology, chemistry, and physics classes. Evaluation of this program indicates that a key feature of an academic skills enhancement program is to engage the students in systematic and daily intense practice in class and to allow them to more quickly gain control over materials.

On a more general note, it is important to realize that participating in such programs and having concrete demonstrations of significant improvements could start a cycle of increasing competence, which could lead to increased confidence and reduced stress, ultimately allowing students to set higher goals, realize their potential, and fulfill their dreams of becoming dentists or medical doctors. 
One final note is that fifty-one of these 179 students have returned for a second summer enrichment program to the University of Michigan School of Dentistry. The goal of this second summer enrichment program, the Profile for Success Program, is to prepare students for taking the DAT, and more recently also the MCAT.

\section{Limitations}

While these results are consistent for nearly all of the years for each subtest, one limitation of this study was the relatively small class size in a given year, ranging from a minimum of fifteen students in 1998 to a maximum of twenty-five students in 2004 and 2005. Although each group in any given year was relatively small, an analysis of the results for the eight years combined demonstrates that summer enrichment programs for students from disadvantaged backgrounds can make a clear difference in these students' academic skills.

A second limitation was that while the same instructor taught these classes each year, the needs of the students differed from year to year, and the instructor therefore adapted the amount of practice in a given area to match the needs of the students. This approach meant that after the pretest results were analyzed, the instructor then decided how to best spend the amount of practice time available for the different skill areas. In addition, students in some years showed more interest in certain areas, such as math, which also affected the amount of time devoted to certain topics because the students asked more questions or contributed more strongly to the discussion on those topics in class.

A third factor that might play a role when interpreting these findings is the fact that the level of the incoming students' academic skills differed. For example, in 2001, the scores at the beginning of the program showed that the students already had very high Nelson-Denny vocabulary and reading comprehension scores compared to the average scores of the students in the other seven years.

Finally, one factor that was not assessed when interpreting these results was the fact that the group dynamics in the different cohorts differed and this may have influenced the overall environment for learning in certain years of the program. It could be conjectured that these differences among the years could have exerted an influence on students' achievement, although the extent of this influence is unknown. In some years, for example, students with undiagnosed but obvious signs of Attention Deficit Hyperactivity Disorder were distracting other group members. While the program budget did not include funds to conduct a comprehensive diagnosis of these students, the academic skills instructor informed these students in their one-on-one counseling session about her observations and made a referral to the university's Office for Services for Students with Disabilities. In addition, some students, especially in the early years of the program, seemed to experience problems with adjusting to the program environment. These students were, for example, not on time for classes or missed classes, which in turn had a negative effect on the work environment as a whole.

One final observation concerns the fact that this enrichment program took place in a dental school environment and that the students had opportunities to interact with dental students and faculty and visit the school's preclinics and clinics. This situation might also have contributed to the success of this program. The program participants lived with their future right in front of them and thus might have seen the value of what they were doing in the academic skills classes for their own academic and professional future careers.

\section{Conclusions}

This study has led us to three conclusions:

1) The data demonstrate that a short summer enrichment program for predental and premedical students from disadvantaged backgrounds can significantly improve students' academic skills in vocabulary, reading rate and comprehension, spelling, and arithmetic/calculations. In addition, it can improve their subject-specific scores in biology, chemistry, and physics.

2) Program evaluations and our experiences with these enrichment efforts indicate the value of individual one-on-one counseling sessions in addition to class instruction. These one-on-one meetings provided opportunities to review transcripts and test results in order to engage the student in setting realistic and relevant goals and in identifying supplementary support mechanisms.

3) Another key element of enrichment programs should be to educate students about appropriate professional behavior and the nature of scholarly inquiry. This aspect of the program should aim at enhancing self-management skills including time 
management, promptness, and organizational and study skills.

\section{Acknowledgments}

This research was supported by HCOP Grant \# 1 D18HP 03112-01 (PI: Dr. Marilyn Woolfolk). We want to thank Dr. Todd Ester, former director of multicultural affairs, for his fantastic outreach and recruitment efforts and his strong support for the Pipeline Program, and program coordinators Patricia Katcher (1998 to 2001) and Charlita Daniels (2002 to 2006) for their excellent work with this program.

\section{REFERENCES}

1. Sullivan LW. Missing persons: minorities in the health professions. A report of the Sullivan Commission on diversity in the healthcare workforce. Durham, NC: Sullivan Commission, 2004.

2. Dinan MA, Armstrong B, Friedman J, Schulman K. Public funds contributing to revenue supporting programs for medical schools. Prepared for the Sullivan Commission, Durham, NC, Duke Clinical Research Institute, 2004.

3. Soto-Greene M, Wright L, Gona OD, Feldman LA. Minority enrichment programs at the New Jersey Medical School: 26 years in review. Acad Med 1999;74(4):3869.

4. Hesser A, Lewis L. Evaluation of a summer prematriculation program for black and other nontraditional students. Acad Med 1992;67(4):270-2.

5. Strayhorn G. Participation in a premedical summer program for underrepresented minority students as a predictor of academic performance in the first three years of medical school: two studies. Acad Med 1999;74(4):435-47.

6. Claycomb CK, Moreland O Jr, Park RI. Recruitment of ethnic and socioeconomically disadvantaged students into dentistry. J Dent Educ 1980;44(4):195-7.

7. Inglehart MR, Katcher PA, Woolfolk MW, Tedesco LA, Ester TV, Green TG, Robinson E. Increasing motivation for dental school: an early approach to the recruitment of disadvantaged students. J Dent Educ 1999;63(1):Abstract \#158.

8. Inglehart MR, Katcher PA, Woolfolk MW, Tedesco LA, Ester TV, Green TG, Robinson E. Preparing future dental students academically. J Dent Educ 1999;63(1):Abstract \#93.

9. Inglehart MR, Woolfolk MW, Katcher PA, Newlin S, Ester TV, Tedesco LA, Green TG. Outcomes of enrichment programs for disadvantaged students: a panel study. J Dent Educ 2000;64(3):Abstract \#135.

10. Inglehart MR, Woolfolk MW, Katcher PA, Newlin S, Ester TV, Tedesco LA, Green TG. Recruiting disadvantaged students to dental school: a system approach. J Dent Educ 2000;64(3):Abstract \#134.

11. Inglehart MR, Woolfolk M, Ester TV, Katcher P, Daniels C, Green T. Preparing disadvantaged students for dental school admission: an outcome analysis. J Dent Educ 2003;67(2):Abstract \#117.
12. Inglehart MR, Woolfolk M, Ester TV, Markel G, Katcher P, Daniels C, Green TG. Recruiting disadvantaged students into dentistry: enhancing motivation, aptitude, and confidence. J Dent Educ 2003;67(2):Abstract \#155.

13. Woolfolk M, Inglehart M, Ester T, Markel G, Daniels C, Katcher P, Green T. Recruiting disadvantaged students into dentistry: a systematic approach. J Dent Educ 2004;68(2): Abstract \#113.

14. Woolfolk M, Inglehart MR, Ester TV, Daniels C, Katcher P, Green TG. DAT test preparation for students from disadvantaged backgrounds: a ten-year analysis. J Dent Educ 2005;69(1):Abstract \#129.

15. Ester TV, Daniels C, Green TG, Inglehart MR, Markel G, Woolfolk MW. Preparing underrepresented students for the dental school admission process. J Dent Res 2006:85(A):Abstract \#1708.

16. Ester TV, Daniels C, Green TG, Inglehart MR, Woolfolk MW. Recruiting disadvantaged students into dentistry: feeding the pipeline. J Dent Res 2006;85(A):Abstract $\# 1734$.

17. Woolfolk M, Ester TV, Green TG, Inglehart MR. Do DAT test preparation courses work? Feeding the pipeline. J Dent Educ 2007;71(1):Abstract \#93.

18. Woolfolk M, Markel G, Ester TV, Green TG, Inglehart MR. Feeding the pipeline: academic skills training for predental students. J Dent Educ 2007;71(1):Abstract \#91.

19. Wilson JE, Murphy L. Premedical and predental enrichment program for minority students, 1969-1996, at Meharry Medical College. Acad Med 1999;74(4):400-7.

20. Gravely T, McCann A, Brooks E, Harman W, Schneiderman E. Enrichment and recruitment programs at dental schools: impact on enrollment of underrepresented minority students. J Dent Educ 2004;68(5):542-52.

21. Bailit HL, Formicola AJ, Herbert KD, Stavisky JS, Zamora G. The origins and design of the Dental Pipeline Program. J Dent Educ 2005;69(2):232-8.

22. Brown JI, Fishco VV, Hanna G. Nelson-Denny Reading Test. Itasca, IL: The Riverside Publishing Company, 1993.

23. Wilkinson GS, Robertson GJ. Wide Range Achievement Test, revision 3. Wilmington, DE: Jastak Associates, 1993.

24. SPSS Inc., SPSS 14.0 Student Version for Windows (SA). New York: Prentice Hall, 2006.

25. Ting SR, Grant S, Plenert SL. The excellence-commitment-and-effective-learning (EXCEL) group: an integrated approach for first-year college students' success. J College Student Development 2000;41(3):353-60.

26. Markel G. Defeating the 8 demons of distraction: proven strategies to increase productivity and decrease stress. Ann Arbor, MI: Managing Your Mind, 2008.

27. Greenbaum J, Markel G. Helping adolescents with ADHD and learning disabilities: ready-to-use tips, techniques, and checklists for school success. San Francisco: Jossey-Bass, 2001.

28. Berardi-Coletta B, Dominowski RL, Buyer LS, Rellinger ER. Metacognition and problem solving: a process-oriented approach. J Exp Psychol 1995;21:205-23.

29. Doughty JD. Improving reading comprehension of underprepared college students. Eric Report ED 3356444 December 1990;73 pp. 
30. Naughton VM. Creative mapping for content reading. J Reading 1993/94;37:324-6.

31. Rosenshine B, Meister C. The use of scaffolding for teaching higher level cognitive strategies. Educ Leadership 1992;49(8):26-33.

32. Schumaker JD, Deshler DD. Validation of learning strategy interventions for students with learning disabilities: results of a programmatic research effort. In: Wong BYL, ed. Contemporary intervention research in learning disabilities: an international perspective. New York: Springer Verlag, 1992:22-46.

33. Zimmerman BJ, Greenberg D, Weinstein CE. Self-regulating academic study time: a strategy approach. In: Zimmerman BJ, Schunk DH, eds. Self-regulation of learning and performance: issues and educational applications. Hillsdale, NJ: Erlbaum, 1994. 